\title{
New dimensions of Risk: Consequences for Management
}

\author{
by Matthias Haller
}

\section{Management and risk}

Anything new always derives its significance from its different nature, from the difference it shows in relation to something that already exists. Thus, this is also the case with the new dimensions of risk which are to be discussed here. The contrast between traditional and new risk raises immediately the question of what the nature of traditional risk is. One will get different answers, depending whether one puts the question to a politician, a member of a military organisation, the civil service, industry, banking or insurance ; indeed, significant differences will be apparent from organisation to organisation. The only common denominator is evident in the statement "As far as we are concerned, risks are made up in a completely different way". The Risk and Security Management Forum will greet such statements with scepticism; we find, however, on the other hand, a common feature linking the different spheres in the problem of risk and in risk management. This topic will be presented for discussion in what follows. That is not to imply that the problems of risk which are discussed below are already manifest in every organisation; the aim is rather to indicate trends which underlie the development of risk potential and of the materialisation of risk in industry and society.

Such a review must start realistically from the proposition that a member of management - from now on, for the sake of simplicity, referred to as "the entrepreneur" pays first and greatest attention to his individual risk problems. The basis of this attitude probably lies in what was described at the opening of this Forum as entrepreneurial self-knowledge. The primitive model of the market economy sees the entrepreneur as an autonomous cell. This autonomy refers not only to making up his mind but also to 
the effect of his activities. He decides the nature and extent of what he offers in the market in complete autonomy but must also bear the consequences, especially the failure of his decisions, himself. Of course, social development has brought about many necessary adjustments and thus narrowed to a certain extent the freedom of action of the entrepreneur. There remains, however, the area which lies between entrepreneurial success and entrepreneurial failure; in brief : entrepreneurial risk.

In a boom period risks are less dramatic, because relative success or failure of entrepreneurial actions are simply reflected by profits which are more or less high. As you know, this comfortable situation has changed fundamentally in a short time. Presently business is working seldom with profitable results and is rather struggling around the zero profit area. In consequence, entrepreneurial risk has become the Number One problem and this is aggravated by the fact that the poor economic situation is accompanied by the necessity of restructuring in important production areas. Efforts to increase flexibility, which are certainly a long-term part of the most important efforts for security, will, in the short-term, also operate as a risk factor.1

In view of this development one is inclined to look for new dimensions of risk solely in the field of entrepreneurial risk. At first glance this appears plausible, yet it turns out to be dangerous on closer observation. Basically nothing has changed here despite the increased tension between success and failure : entrepreneurial risk has in essence remained the same, though it has become more arduous to handle after a period of easier opportunities. On the other hand the remaining risks of the enterprise and of other goal-oriented systems have greatly increased, without the inherent determining factors and trends yet becoming clear.

The reflections which follow seek thus to establish the thesis that traditional entrepreneurial risk is indeed becoming more important, but that, at the same time, the way is being paved for a much more dangerous development in the field of the remaining risks of business and society, which need adequate analyses and management.

\section{The starting point : grouping risks}

In considering the above thesis, the question immediately arises: what are to be understood as " remaining" risks? In order to start from existing concepts, we can make use, as a first step, of the division that was used by the founders of the insurance and loss control related concept known as "risk management". Influenced by insurance management, originally only "pure" risks, i.e., those with the possibility of a loss only, were considered as the subject of "risk management" ; on the other hand, "speculative" risks, which involve a possibility of gain, were excluded from consideration. According to this division, risks of fire or liability are typically " pure" risks ; research, development and market risks are typically " speculative".

The proposition that "pure" risks are connected only with loss, but not with success, has led to intense academic discussion. Representatives of probability theory and

1 Cf. the article of Friedrich Thomé, p. 35 of this issue. 
of decision theory in particular have characterised the distinction as arbitrary, for the boundary between "pure" and "speculative" risks depends solely on where zero is placed on the scale. In practice, too, the boundaries will be obliterated: so that political risk can be treated with the techniques of "risk management", although it is classed among the significant business risks ; on the other hand, for example, neglect of fire consequential loss endangers the existence of the enterprise, although it would plainly be reckoned as "pure" risk. On this basis the distinction between "pure" and "speculative" can more and more often be dispensed with and in the most recent literature it will either be rejected or not mentioned at all.

If one looks at it purely logically, one will have to agree with this opinion : every business decision will produce different possible outcomes. If these possible outcomes are set out in a probability distribution, some will lie to the right, others to the left of the zero point - success or failure corresponding respectively to the two possibilities. No risk is in itself positive or negative only. The decisive factor is simply how severe a fluctuation into the negative will affect the position of the enterprise.

Logically compulsive as this objection to the distinction between "pure" and "speculative" risks may be, from the practical point of view (and usually also that of realistic scholarship) there are objections, which could in a situation of increased risk, be decisive for management :

1. It presupposes that the management of the enterprise will approach all risks in basically the same fashion; that their implications for the enterprise are the only decisive factor;

2. In other words, it presupposes that all important risks will be included in the decision process.

These statements appear so obvious that few words either in the practice or in the academic world will be wasted on them. The formal logic of choice fills volumes of academic analyses, yet usable concepts are very scarce.

The oft-quoted passage from Peter Drucker's "Management Tasks" shows this too: "The main goal of a management science must be to enable business to take the right risk. Indeed, it must be to enable business to take greater risks - by providing knowledge and understanding of alternative risks and alternative expectations; by identifying the resources and efforts needed for desired results against expectation, thereby providing means for early correction of wrong or inadequate decisions." 2

What is formulated so obviously and comprehensively in management literature is unfortunately not to be found easily in current examples and cases. In actual practice an integrated analysis of risks in terms of their disturbance potential are rarely taken into consideration. Many major possibilities of disturbance are often not analysed until the decisions have already been taken. In this way, for example, vulnerability to business interruption, burglary and sabotage will often not be considered before the final architectural drawings for a new building have been submitted.

2 Drucker P., «Management Tasks, Responsibilities and Practice », London, 1973. 


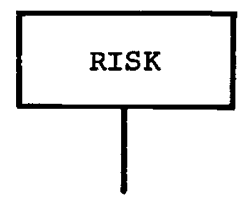

The possibility that expectations will not be fulfilled;

possibility of disturbance

no

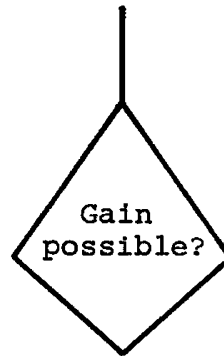

yes

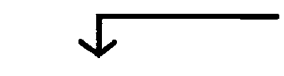

"pure" risk

"speculative" risk

psychic dimension

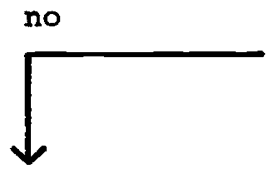

threatened

marginal

conditions

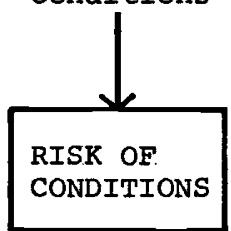

yes

to the outcome

of

action?

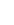

V threatened outcome of action

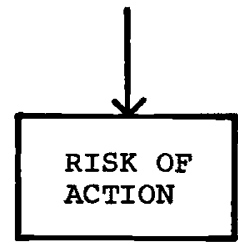

Fig. I Risk Structure

6 


\section{Risk of action and risk of conditions}

Attitude and behaviour towards a risk problem are often determined by a psychic factor : the manager has a closer relationship with a group of risks, the more closely a threat to the success of the business is related to the action. Such risks are referred to below as risks of action : the remaining risks we will call risks of conditions, that is, risks which follow threatened surrounding conditions (Fig. 1).

The two concepts of "speculative" and "pure" risk are thus clearly contrasted with the two concepts of "risk of action " and " risk of conditions". Whether or not there is a possibility of gain, the latter expresses the connection between the planned action and the risk associated with it. Both risks of action and of conditions are linked with the psychic attitude of managers : the risk of action will directly include the Opportunity/Threat Profile and become as such a constituent of the actual decision process. On the other hand the inclusion of the risks of conditions requires a certain

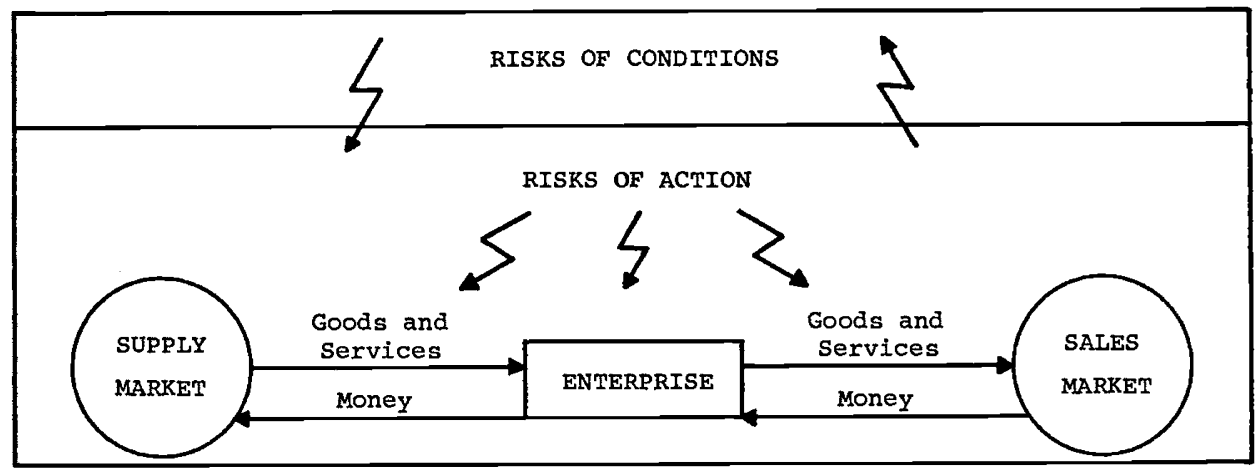

Fig. 2. Risks of Action and of Conditions of the Enterprise

additional effort and an almost malicious imagination : the effort is only worthwhile if the risks of conditions are considered to be equally capable of threatening, indirectly, the success of the whole action. From the psychological point of view, it can easily be seen that managers will sooner acknowledge the risk of action than the risk of conditions. Discussions about risks appear worthwhile when there is an expectation of success; threats, on the other hand, which are only partial from the disturbance aspect, are more likely to be ignored, their management deferred or tackled halfheartedly, or delegated with no clear objective set.

From this it may be deduced that risks of conditions can, therefore, attain a higher degree of disturbance because they are not immediately considered.

There are three main considerations to be made about this point :

1. Discussion of risks of conditions is often intuitive. This is necessarily so because of the lack of data about really important decisions and disturbance potentials. But intuition always requires a stock of experience to which the unconscious evaluation of alternatives refers back. Risks of conditions are not the normal background of a manager but of a risk specialist. Experience is, therefore, lacking and with it the basis of intuitive decision. 
2. Risks of conditions also present specific problems if they are analysed consciously and at considerable expense. Again there is a lack in most organisations of experience of specific risks which have materialised. This is true not only of an army without war experience ; in the civilian sphere, too, large risks nor-mally materialise only in rare cases, so that in analysing large losses management has to use information from outsiders. A transfer of information of this kind already exists in some areas but it is stuffed into the cupboards of secrecy and of the transferability of information acquired. No system lays down management assumptions which are completely identical with those of another. Because the most serious cases of disturbance are almost due to an unfortunate combination of technical and human conditions, in the same way the consequences for security must also be determined case by case. Similarities in vulnerability to disturbance must not be based only on similarities of a particular industry or type of production but on a multiplicity of external factors.

3. Risks of conditions present special problems in connection with their insurability and the institution of insurance. Risks which affect the surrounding conditions of management activity are, in practice, insurable today and covered if disturbance occurs, if they are not demonstrably caused by the insured himself. (This simplified description of "insurability" can and must suffice here, but academically formulated definitions often prove to be unreal in practice.) Now, insurable risks are by definition risks whose effect is caused "fortuitously". Normally there will be no responsibility attached to something caused, so to speak, "fortuitously ", and if there is no responsibility no one is held accountable. In view of such a lack of accountability, the manager hardly feels obliged to concern himself in any detail with risks of conditions. This internal absolution of management, in simple economic terms a valuable function of insurance, will encourage even more the neglect of risks of conditions, so long, at least, as losses do not reach a level which threatens the existence of the company, i.e., as long as they can be transferred.

All three facts - (1) intuitive management without experience, (2) the difficulty of obtaining information for the purposes of analysis, and (3) the lack of personal accountability for occurred disturbances, confirm that risks of condition are especially dangerous from the psychological point of view.

This implies a condition which is clearly a necessary one but in no way a sufficient one, if an increased actual threat from risks of conditions is to be confirmed. It requires evidence that the potential for disturbance from risks of conditions has increased objectively; in other words that risks of conditions in industry and society can reach levels which threaten existence. This evidence is the more difficult to obtain because up to now events of this kind have not happened often - it may be that we have not classified cases which do exist as such, because they have, so to speak, a delayed action effect. Again it may not be possible to prove it conclusively but such a trend appears to exist. Latest developments in the field of risks of conditions are worth consideration, not only on the part of industrial management but also of the governmental, administrative and military spheres. The intensification of risk takes place in two dimensions at once; on the one hand in the economic technological field, and on the other hand in the social or societal field. 


\section{The economic-technological dimension : trend towards increased vulnerability}

We can quickly comprehend the economic-technological dimension. Orio Giarini has written a paper ${ }^{3}$, the main conclusion of which consists of the recognition that the highly-industrialised economic system is on the way to progressively increasing vulnerability irrespective of the prevailing economic situation. This reasoning is, essentially, on the following lines:

1. The first Industrial Revolution comprises in fact only the last phase of a development which has been taking place since prehistoric times. Man stumbles across new techniques by accident and makes use of them. For this reason, pessimistic forecasts about the future of mankind are frustrated time and time again.

2. The second Industrial Revolution is crucial to the present-day situation. In it science becomes for the first time in history the basis of new technology. Research and development becomes an independent factor in production which finally determines economic growth. Expenditure on " $R$ \& D" of course takes on new dimensions. If the investment succeeds, the gain is enormous; if not, then the survival of the whole enterprise is endangered. Add to this the fact that successful research is only productive in the long term. The introduction of new technology gives a dynamic impression, a rapid succession of changes take place, the origine of which, however, lies very far back.

Two states of affairs arise from the second Industrial Revolution :

(a) unprecedented economic growth in the expansion phase;

(b) an economy with unprecedented vulnerability the consequences of which are making themselves apparent for the first time, in the maturity phase.

3. In regard to the estimation of the potential for disturbance the thesis that the limitations to science-based technology are carried over into the economic sphere is of most interest to us :

(a) Never was the adaptation of supply to demand so difficult and time-delayed as it is today;

(b) Diminishing returns are to be observed from research development; writing off in the shortest possible time leads to a compulsion to produce to the maximum and uninterruptedly during the successful period;

(c) The use of modern technology requires better, faster and more concentrated forms of production. Specialisation results at the expense of flexibility;

(d) The relative importance of production falls : logistical problems become noticeably more important;

(e) Environmental problems (increasing length of recycling periods, increased costs of environmental protection, more stringent liability situations) also appear.

3 See Giarini, O., Lettre d'Information N. 19, Geneva Association, and "Economics, Vulnerability and the Diminishing Returns of Technology », Geneva Papers N. 6, October 1977. 


\section{What are the consequences for risk evaluation?}

All five circumstances contribute to the increased vulnerability of the modern economy. Objectives must be formulated further ahead, ways of attaining them are to a large extent determined in advance, so that the effects of disturbance become more and more extensive. It is not merely the individual enterprise which is subject to this trend toward large risks; diminishing autonomy leads to an intimate connection with the environment, to a linking of positive and negative impulses. Larger systems, such as communities, cantons and federal States, energy supply and news transmission systems are drawn into increased vulnerability : risks to individual economic and administrative units spread from the micro-economic into the macro-economic sphere. (In this way, for example, the 1974 explosion at Flixborough in addition to all the direct damage, involved a reduction in the supply of raw materials for nylon, which brought about a noticeable worsening of the British balance of payments.) If the thesis of the increased vulnerability of our highly-industrialised economy seems plausible, it remains to be proved, with regard to the evaluation of large risks of this kind, how far the vulnerability makes itself felt in risks of action or, on the other hand, in risks of conditions.

The result is plain: with the exception of point (a) - more difficult adaptation of supply - all the circumstances make up a picture of disturbances which are only indirectly connected with the traditional management of the enterprise. In consequence, in the course of this development, risks of conditions are assuming a greater importance. Even if individual managements recognise and analyse the problems, the management of risk becomes increasingly difficult. On the one hand, many centres of disturbance come from outside the company, while on the other hand, the internal ones can be classed as fortuitous events. Management ought in particular to be intensively concerned in the years ahead with the problem of controlling or reducing fortuitousness.

Because of some large loss events general management is more and more obliged to pay attention to "accidents", whereby not only a specific risk must be controlled, but also its environment which contributes largely to the dimension of the loss.

As far as the specific risk - and thus the determination of the cause of the disturbance - is concerned, increased requirements as to the safety systems and the safety procedures will be laid down. Analysis of the large loss events of recent years brings to light a common element, which safety practice and safety science have so far apparently taken too little into consideration: even perfect technical safety systems cannot prevent (and indeed may on the other hand facilitate) a man reacting wrongly in an emergency and under stress, because he lacks experience of conditions in this situation and he loses control because of the factors of disturbance. The aircraft collision at Santa Cruz is a sad confirmation of this view. It had already been set out by a committee of inquiry into the explosion at Flixborough.

Analysis not only of the specific risks, however, but also, and to a greater extent, of the risk environment, makes acceptance of "fortuitousness" even more questionable. The cause of risk may not have a catastrophic effect until it happens under circumstances which condition the dimension of the disturbance. Production sites which pollute the environment in the middle of a town and in the desert may be completely identical as far as a specific risk is concerned, but they produce very different disturbance potentials because of their risk environment. It is often - and this must be clearly established - not entrepreneurial but political management which bears the main 
responsibility for this state of affairs. For a long time the seriousness of the increased vulnerability was not recognised and correspondingly planning and legislation are often belated. State institutions, both civil and military, will have a greater interest in an early analysis of vulnerability of this kind, as they are enmeshed more closely, through logistical channels, with the economic system.

Let us attempt to understand the consequences of the development of risk in the technical-economic dimensions : what from the point of view of the individual institution appears as a risk of conditions, as a disturbance, caused by accident, of the marginal conditions, appears, viewed globally, as a clear trend towards increased vulnerability. A connection, which is becoming ever closer, between the enterprise and its technological and economic environment increases dependencies, as a result of which disturbances can be transferred from outside to the enterprise but also from the enterprise toward the outside (Fig. 3).

The unstabilising element is characterized by the fact that small disturbances in critical paths of the operation can paralyse whole sectors of industry and the State. The rarity of such cases does not diminish the potential disturbance. As the probability

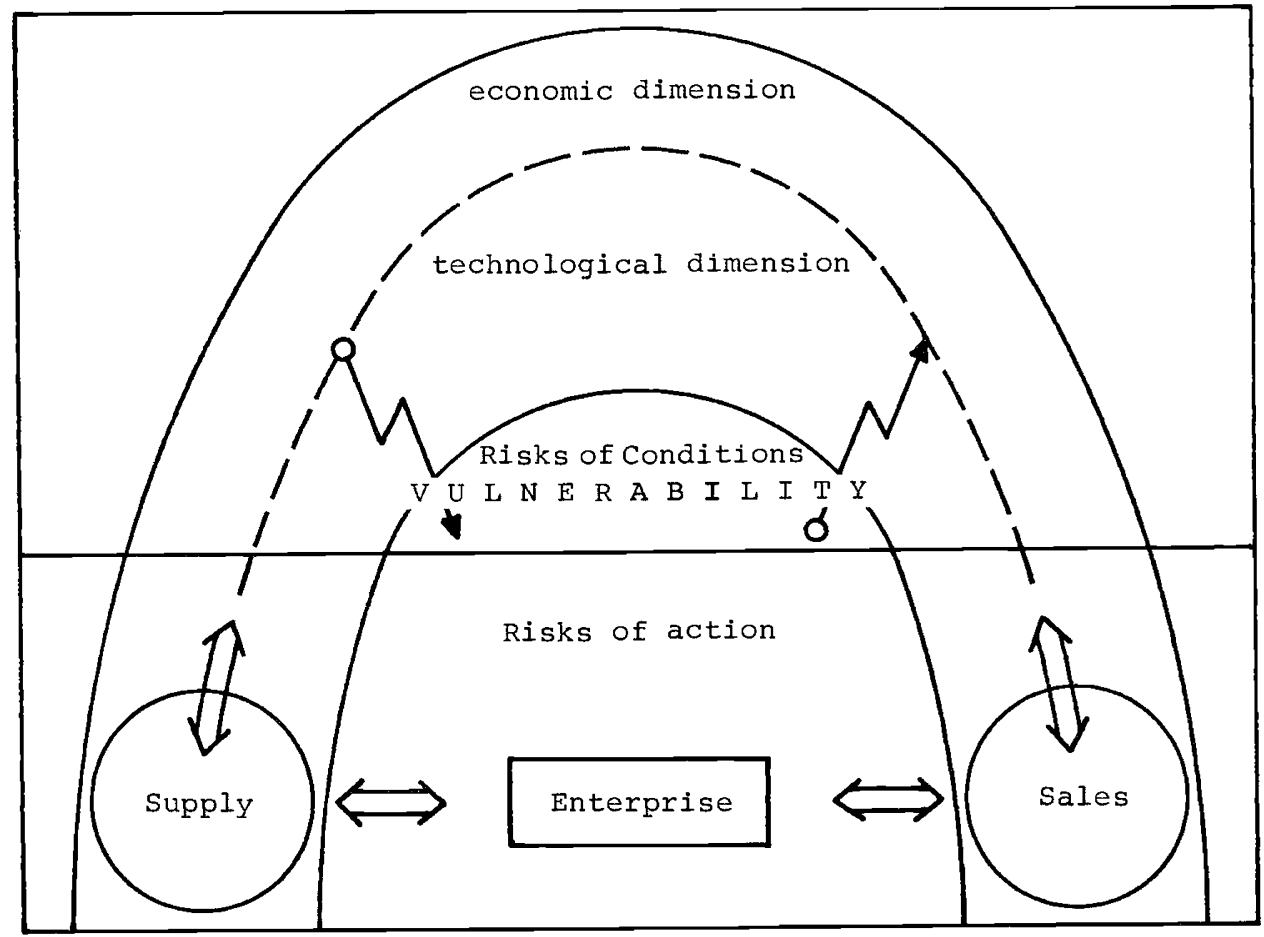

Fig. 3 Increased Vulnerability as Indicator of the Close Connection with the Technological and Economic Environment. ${ }^{4}$

4 Drawing after H. Ulrich / W. Krieg, St. Gall Management Model, 3rd Edition, 1974, 
becomes even lower, to the same extent do we lose stochastic security and thus the global equilibrium provided by the law of large numbers. In this way, the risk problem takes on an either/or form, which up till now has been evident primarily in the field of military strategy..$^{5}$ Equally, human behaviour, whether as supporters or consciouslyacting opponents, becomes more significant. As we take the human factor into consideration, we are pushing forward into the social dimension.

\section{The social dimension : social and socio-political disturbance}

The increased vulnerability of our technico-economic systems, which can be objectively observed, cannot fail to have an effect on the social dimension. Now it is not clear how the individual reacts with what is external to him. He does not find things out only by himself, but is widely guided by the information transmitted to him by the media. The way in which the increased risk potential will affect society will thus be finally determined by the information systems and the form of information treatment.

Now our public information systems are either commercialised or, if they work independently as State institutions, are in competition with similar organisations for the listener's or viewer's favour. The obligation to "produce" information which will have an effect on the public leads to overemphasis on accident and loss information. Serious and catastrophic accidents, especially, receive particular attention because of their telegenic nature. They will be reproduced a million-fold via the media and impress themselves on the conscious and subconscious mind of the public as everyday happenings and as a direct internal disturbance. In the future, as now, statisticians will waste their efforts trying to make us conscious of the fact that driving to the airport is much more dangerous than the flight which follows. The roll of dead and injured on European roads at Easter will attract no one's attention in the way perhaps that the aircraft collision at Tenerife did. It would be extraordinary to their credit if psychologists could go on to magnify this schizophrenia into a public consciousness of risk. Perhaps there could be valuable consequences for safety management in business and society.

Definitive results are still not at our disposal and already a further aggravation of risk can be observed in the social dimension. Until a short while ago it was only relatively rare accident and loss events that received attention ; recently concentrated information and discussion about risk as such has been enough to evoke general apprehension. The response that a particular risk has never yet affected anyone - not least because of safety provisions - has made little headway. The individual and society both show an astonishing readiness to come to terms with accidents which have already happened. On the other hand, their uncertainty about the materialisation of risk involves a mental load for which they are unprepared. In this situation, a feeling of powerlessness easily turns into hatred for and revolt against the economic, technological and political system.

(It is very instructive to examine the "Seveso" case from this point of view. If it is compared quite soberly and objectively with other loss events, one must conclude that, on the basis of the number of dead and injured so far reported, it should not be classed as a large loss. Its " social explosion" first became apparent when, three weeks

5 For more detailed treatment see M. Haller «Sicherheit durch Versicherung? 》 I-VW Schriftenreihe, Band 1. Berne/Frankfurt, 1976, pp. $19 \mathrm{ff}$. 
after the release of the trichlorophenol containing dioxin, strikes and discussions as by-products of the accident penetrated from the technological into the social dimension. Here again it has remained closely bound up with it in public discussion.)

The penetration of risk from the technico-economic into the social dimension will naturally be facilitated in a society with a greater degree of political freedom and freedom of information. It will also be contributed to particularly by those groups who want to reform society as a whole and who gladly accept weaknesses - say, risks of the society as reasons for calling everything into question. Because they can cloak their daily demands to some extent, as those of politicians and citizens who are properly and legitimately involved, political disturbance will have to be particularly carefully and impartially analysed.

The result for the social dimension of risk is thus as follows :

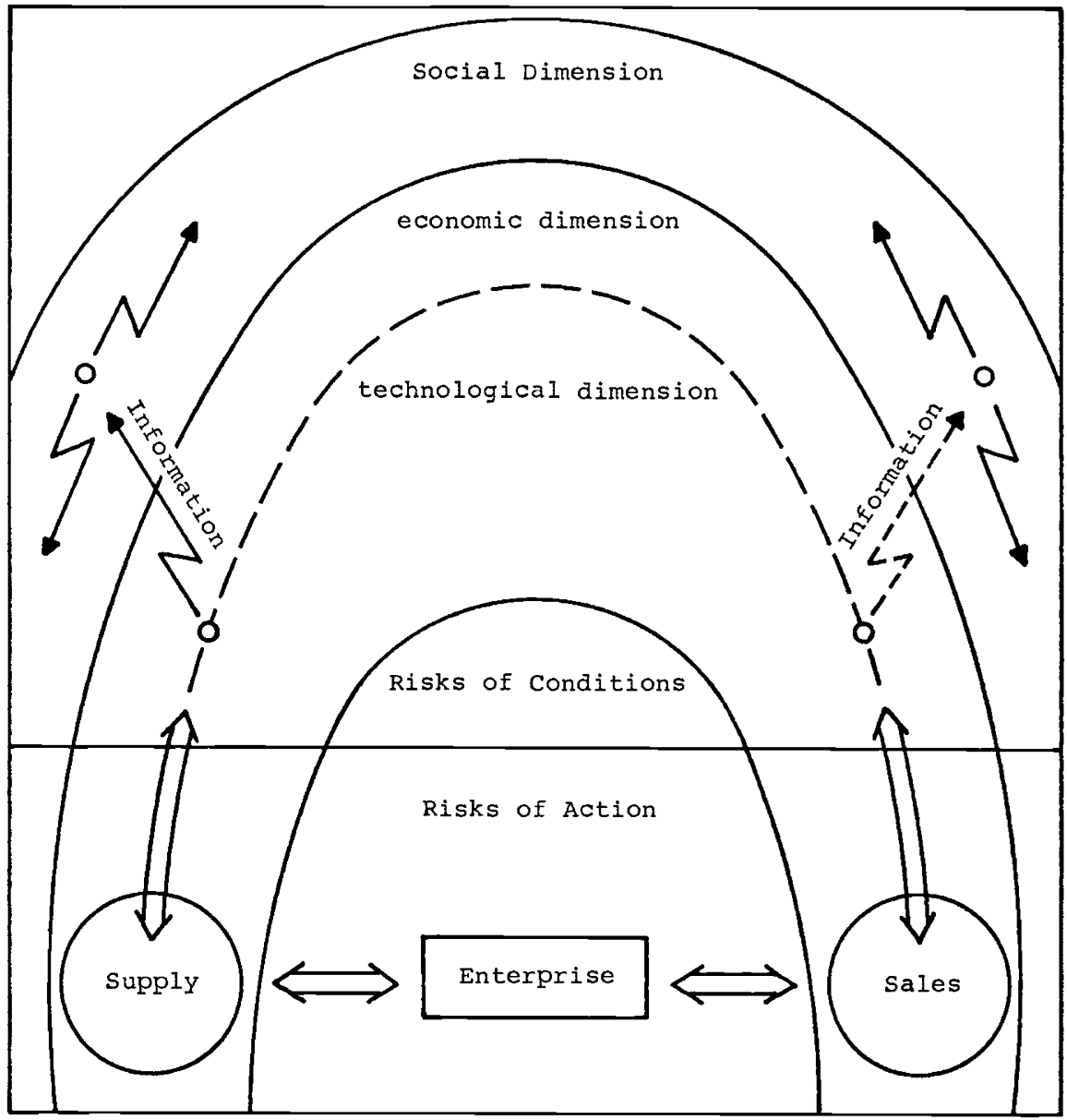

Fig. 4. Increased Potential for Disturbance in the Social Dimension 
Those few major accidents and major losses which actually occur, most of which originate in the area of risks of conditions, achieve, because of the way information is handled, a disproportionate importance. Nevertheless - or for that very reason - they must be given corresponding weight in a society with democratic decision processes. Recently, more information about large risks (which had not materialised) has led to similar events. This additional load, on top of the increasing tide of particular reasons for anxiety, can easily swell into a general apprehension.

The threshold of sensation for such a reaction is in the process of being permanently lowered, which disturbs equally the security of society and political balance. Risks thus acquire $a$ dynamic of their own by their very existence in the social dimension. We can only counter to them at the highest level, i.e. at the level of society : risk management understood in its literal sense, must in the final analysis be applied at all levels.

\section{Consequences and conflicts}

It would be impossible to derive clear consequences for management decisions and management behaviour in circumstances of increased risk from such complex relationships. Let us now go back to our starting point, to entrepreneurial behaviour. Now as ever, it is determined first of all by the success of the action and here is the driving force of all efforts. Nevertheless, it compels, at the same time, an increased attention to risks of conditions, because, indirectly, they threaten the framework of economic and State activity.

Now, as far as the concrete security goals are concerned, one can adopt an individual and a global viewpoint. The two need not correspond in every respect, for it is easily possible that a risk which appears individually to be bearable and creative, must be avoided from a global point of view and the reverse situation is also perfectly understandable.

The individual security measures of a particular institution can be divided according to whether they relate to potential for disturbance which already exists, or to "planned actions". If an activity creates a serious disturbance potential for the particular institution or for the environment, one must require corresponding security measures to be fully integrated into the management. This sounds as if it were a matter of course, yet experience shows that genuine risk management only applies in very rare cases. It is a precondition that security goals must figure in company policy and affect company planning so as to be taken into account, particularly in investment and other requirements. The risk management organisation must not be limited to the nomination of a risk manager but must affect the list of duties of the whole management; the risk management co-ordinator will assume particular responsibility for transfer of information and for training but in no case for security as a whole. This attaches, and will continue to attach, to managers of all kinds.

When it comes to planned actions the risk management function will be realised most completely if risks of conditions, too, are considered at all stages of planning and appropriate modifications are specially authorised.

A risk avoidance decision is certainly the most difficult one. It is equivalent to the renunciation of an action, having regard to the risk. Careful and systematic risk analysis 
ought to make such decisions easier. The experience of specialists - especially those engaged in the nuclear power industry and in air transport - shows, however, that the general public is less and less disposed to accept too great a difference between the originally estimated disturbance potential (largest possible accident) and the residual environmental risks. Risk management, which up to now has concerned itself primarily with the reduction of possible disturbance, will, in future, have to tackle much more the possibilities of reducing the vulnerability of the system.

This involves the global aspect of security. The reflections above have outlined the transition of increased vulnerability in the technico-economic sphere into societal dimensions. Yet we do not know the final consequences, which suggest a conflict of objectives, to which adequate attention cannot be given here. Security and control measures in large systems can, if they are to be effective and prevent losses, infringe on the private sphere of the citizen. But values will thereby be impaired, which we in the Western nations consider to be of the highest importance. A conflict between freedom and security will be manifest which we in industry alone neither can nor must resolve. If it is to be discussed at the highest levels of politics and law: it is a fundamental condition, that the risk management approach should be introduced to these circles too.

An extremely unstable equilibrium will thus result from the future interaction between entrepreneurial action on the one hand and socio-economic reaction on the other. These are the "new dimensions of risk". Two factors will be decisive whether an equilibrium is maintained, whether, in other words, the creative aspect of risk remains valid : the potential for disturbance on the one hand, risk consciousness on the other. Perhaps it is a not insignificant decision for managers to what extent they will be personally engaged in both areas in the future. 